\title{
lodine- 125 seed implantation and allogenic natural killer cell immunotherapy for hepatocellular carcinoma after liver transplantation: a case report
}

This article was published in the following Dove Press journal:

OncoTargets and Therapy

\section{Silun Xie' \\ Zhengyi Wu' \\ Liang Zhou ${ }^{2}$ \\ Yingqing Liang ${ }^{2}$ \\ Xiaohua Wang ${ }^{2}$ \\ Lizhi Niu \\ Kecheng $X u^{2}$ \\ Jibing Chen ${ }^{2}$ \\ Mingjie Zhang'}

'Research and Development Department, Shenzhen Hank Bioengineering Institute, Shenzhen

518004, China; ${ }^{2}$ Department of Central Laboratory, Fuda Cancer Hospital of Jinan University, Guangzhou 5I0665, China
Correspondence: Mingjie Zhang

Shenzhen Hank Bioengineering Institute, Building I I9-5F, 72 Guowei Road,

Shenzhen 5I8004, China

Email ming.zhang@hankbio.org

Jibing Chen

Department of Biological Treatment Center, Fuda Cancer Hospital of Jinan University, Building 7A, 2 Tangde West Road, Guangzhou 510665, China Email864623288@qq.com

\begin{abstract}
For advanced hepatocellular carcinoma (HCC) patients, liver transplantation (LT) is an optimal treatment with limitation of high risk of tumor recurrence related to the immunosuppressive chemotherapy as usually recommended. In this study, a 29-year-old man suffered from HCC recurrence after LT. He underwent radiotherapy (total dose: $45 \mathrm{~Gy}$ ) but had no significant response. Then, he received iodine-125 seed implantation combined with allogenic natural killer (NK) cell immunotherapy. Liver function, immune function, circulating tumor cell counts and computed tomography scans were evaluated to determine the clinical effect. We found that this combined treatment produced enhanced immune function of the patient and reduction in tumor size. This is the first report of an efficacy and safety study about clinical regimen comprising allogenic NK cell immunotherapy combined with iodine-125 seed implantation for the treatment of HCC recurrence after LT.
\end{abstract}

Keywords: hepatic carcinoma, iodine seeds implantation, natural killer cells, allogenic

\section{Introduction}

Treatment of liver metastases after liver transplantation (LT) represents a clinical challenge. Most patients with hepatocellular carcinoma (HCC) are not completely free of the risk of tumor recurrence after LT. Currently, chemotherapy is the general therapeutic strategy; however, posttransplant immunosuppression following chemotherapy remains a major problem. Therefore, alternative therapies are urgently required for immunosuppressed HCC patients.

Implanting iodine-125 seeds into the tumor sites has been widely used for the treatment of liver cancer. ${ }^{1}$ Iodine- 125 releases $27.4-31.4 \mathrm{keV}$ X-rays and $35.5 \mathrm{keV}$ $\gamma$-rays, which kill tumor cells through free oxygen radical generation and ionization. ${ }^{2}$ However, collateral damage to surrounding tissues and organs is reduced because iodine-125 is only effective over a $17 \mathrm{~mm}$ radiation radius. ${ }^{3}$ Furthermore, iodine- 125 seed implantation promotes anticancer immune responses, which activate $\mathrm{CD}^{+}$and $\mathrm{CD} 4^{+}$cells. ${ }^{4}$

Natural killer (NK) cells are one of the most efficient components of innate immunity and also participate in adaptive immunity. ${ }^{5,6} \mathrm{NK}$ cells exert efficient antitumor activity and have been exploited for anticancer therapy using an adoptive immunotherapy approach. ${ }^{7-10}$ Moreover, it is advisable to select killer cell immunolobin-like receptor (KIR) and its ligand, human leukocyte antigen (HLA) class I molecules mismatched alloreactive blood donor. ${ }^{11}$ 
Here, we report the case of a 29-year-old Hungarian man with HCC recurrence after LT. We assessed the clinical efficacy and safety of iodine-125 seed implantation combined with allogenic NK cell immunotherapy as a potential therapeutic strategy.

\section{Case presentation}

This clinical trial was approved by the ethics committee of Guangzhou Fuda Cancer Hospital. According to the Declaration of Helsinki, written informed consent was obtained from the patient for publication of this case report.

Here, we report the case of a 29-year-old Hungarian man who underwent LT following resection of a sizable hepatic tumor in November 2014. Recurrence occurred in February 2015. The patient accepted radiotherapy (total dose: 45 Gy) from June 2015 to August 2015; however, the clinical result was unsatisfactory and the patient opted for further treatment with iodine-125 seed implantation combined with allogenic NK immunotherapy.

\section{lodine- 125 seed implantation}

Iodine-125 seed implantation was performed by Dr L. Zhou and his assistants. Following local anesthesia with the patient in a supine position and electrocardiogram (ECG) monitoring, iodine-125 seed strands were prepared for transplantation according to the computed tomography (CT) findings. Ten seeds, each with an activity of $0.7 \mathrm{mCi}$ and a half-life period of 60.1 days, were implanted at the tumor border at intervals of $0.5 \mathrm{~cm}$. The number of seeds deployed was determined based on the tumor size (matching dose $\sim 120 \mathrm{~Gy}$, usually $\leq 20$ particles).

\section{Allogenic NK cell immunotherapy}

For allogenic NK cell immunotherapy, the donor (the patient's kinsfolk) was selected based on genotyping mismatch between recipient patient peripheral blood KIRs and HLA class I molecules of allogenic donor. ${ }^{12-17}$ KIR and HLA class I molecule typing were performed on the peripheral blood from allogenic donors and the recipient using the TIANamp Blood DNA Kit (Tiangen Biotech Co., Ltd., Beijing, China) and KIR/HLA-Cw Genotyping Low Resolution Kit (PCR-SSP; Super Biotechnology Developing Co., Ltd., Tianjin, China). KIR/HLA-Cw mismatch was defined as absence of one or more HLA alleles known to be ligands for the inhibitory KIR typing, using previously published criteria. ${ }^{18}$

\section{Highly activated NK (HANK) cell preparation}

HANK cells were prepared under good manufacturing practice (GMP) conditions using clinical-grade reagents.
The human NK cell in vitro culture synergistic kit (HAHK Bioengineering Co., Ltd., Shenzhen, China) was used to co-stimulate expansion and activation of NK cells in the blood mononuclear cells (MNCs) according to the manufacturer's instructions. ${ }^{15-19}$ Briefly, $\sim 50 \mathrm{~mL}$ peripheral blood from the donor (the patient's kinsfolk was informed) was collected. The blood was transferred to a $50 \mathrm{~mL}$ conical tube and centrifuged at $600 \times g$ for 15 minutes. The plasma in the supernatant was collected into a $50 \mathrm{~mL}$ conical tube. Equal volume of saline was added to blood cells in the bottom, and the cells were resuspended for lymphocyte separation. The plasma tube was transferred into $56^{\circ} \mathrm{C}$ water bath for 30 minutes, made to stand on the bench top till the tube temperature was $<37^{\circ} \mathrm{C}$ and centrifuged at $400 \times g$ for 10 minutes; the supernatant was then transferred into a new $50 \mathrm{~mL}$ conical tube and stored at $4^{\circ} \mathrm{C}$ for further applications. The plasma tube stored at $4^{\circ} \mathrm{C}$ for $>12$ hours was centrifuged again, and only the supernatant was used. In all, $20 \mathrm{~mL}$ of human lymphocyte separation solution (Haoyang Biological Manufacture Co., Ltd., Tianjin, China) was transferred into two $50 \mathrm{~mL}$ conical tubes. Carefully equal volume of the blood cell suspension was laid onto the lymphocyte separation solution in two $50 \mathrm{~mL}$ conical tubes and centrifuged at $600 \times g$ for 15 minutes. The lymphocytes in the middle layer were transferred into a $50 \mathrm{~mL}$ conical tube and washed twice with saline. The total cell number was counted. NK cell culture media consist of $1 \mathrm{~L}$ X-Vivo 15 serum-free medium (Lonza, Walkersville, MD, USA), one tube HK-002 and self ( $5 \%$ for initial $200 \mathrm{~mL}$ medium and then reduce to $1 \%-2 \%$ ). Tube HK-001 contains membrane chimeric active cellular factors. One tube of HK-001 is good for $4 \times 10^{7}$ lymphocyte initial culture. The HK-001 tubes needed were calculated according to the lymphocyte numbers. HK-001 was taken out of liquid nitrogen or $-80^{\circ} \mathrm{C}$ freezer and immediately put into $37^{\circ} \mathrm{C}$ water bath for recovery. Then, it was centrifuged at $350 \times g$ for 5 minutes and the supernatant was deserted. The precipitate was washed twice with saline. The precipitate with $\sim 3 \mathrm{~mL}$ NK cell culture medium was resuspended. Then, NK cells were cultured with following procedures. On day 1 , $4 \times 10^{7}$ lymphocytes, $50 \mathrm{~mL}$ NK cell culture medium and 1 tube of recovered HK-001 in a T175 culture flask (Corning Incorporated, NY, USA) incubated at $37^{\circ} \mathrm{C}$ with $5 \% \mathrm{CO}_{2}$ were mixed. On day $3, \sim 30 \mathrm{~mL}$ of $\mathrm{NK}$ cell culture medium was added to the T175 flask. On day 5, 60 mL of NK cell culture medium was added to the T175 flask and the cell concentration was adjusted to $\sim 1 \times 10^{6} / \mathrm{mL}$. On day $6, \sim 60 \mathrm{~mL}$ of the NK cell culture medium was added to the T175 flask and the cell concentration was adjusted to $\sim 1 \times 10^{6} / \mathrm{mL}$. 
On day $7, \sim 50 \mathrm{~mL}$ of the NK cell culture medium (1\%-2\% plasma concentration) was added to the T175 flask. The cell number was counted. If the total cell number was $>6 \times 10^{7}$, a tube of recovered HK-001 was added; if the total cell number was 3-6×107, a tube of recovered HK-001 was added on the eighth day. The first sterility test was performed. On day 8 , the total culture from the T175 flask was transferred to the $2 \mathrm{~L}$ cell culture bag (Haoyang Biological Manufacture Co., Ltd.). Approximately $200 \mathrm{~mL}$ of the NK cell culture medium was added to the cell culture bag. On days 9, 10 and $11, \sim 150 \mathrm{~mL}$ of the NK cell culture medium was added to the cell culture bag each day. On day $12, \sim 350 \mathrm{~mL}$ of the NK cell culture medium was added to the cell culture bag. The quality control tests were performed including cell viability, NK cell purity, endotoxin, activity (cytotoxicity) and sterility. ${ }^{16,17}$ On day 13, HANK cells were harvested. The total cell number ( hould be $\sim 1 \times 10^{10}$ ) was counted. The cultures were collected into $450 \mathrm{~mL}$ conical centrifuge tubes. Cells were precipitated and washed once with saline. The cell concentration was adjusted to $\sim 2 \times 10^{7} / \mathrm{mL}$ with cell infusion solution ( $400 \mathrm{~mL}$ saline with $1 \%$ human serum albumin and $6 \mathrm{~mL}$ HK-003). Approximately $3-5 \times 10^{9}$ HANK cells were harvested into a blood transfusion bag each day for infusion at a concentration of $\sim 2 \times 10^{7} / \mathrm{mL}$. The release tests were performed on each bag of cells.

\section{Therapeutic procedure}

Iodine-125 seed implantation was carried out on June 2016 , and the cultured HANK cells were infused intravenously from July 2016 to October 2016 (Table 1). Two courses of treatments were performed monthly. Each course with three infusions was delivered consecutively over 3 days. The patient received six courses of treatments (18 infusions) in the therapeutic process.

Table I Clinical details and therapeutic procedure

\begin{tabular}{|l|l|}
\hline Time & Therapy \\
\hline November 2014 & LT \\
\hline February 20I5 & Recurrence \\
\hline June-August 2015 & Radiotherapy \\
\hline June 20I6 & lodine-I25 seed implantation \\
\hline July-October 2016 & Allogenic NK cell immunotherapy \\
\hline June-October 2017 & Subsequent visit \\
\hline
\end{tabular}

Notes: Peripheral blood samples were collected from the patient for HANK cell isolation after iodine- 125 seed implantation. After I month, the cultured HANK cells were intravenously infused in six courses (I8 times) from July 2016 to October 2016.

Abbreviations: LT, liver transplantation; NK, natural killer; HANK, highly activated natural killer.

\section{Safety and curative effect evaluation}

\section{Adverse events}

The most common adverse reactions were recorded that included local (pain and retroperitoneal errhysis) and systemic (chills, fatigue and fever) reactions.

\section{Liver function}

Liver function was evaluated based on the levels of ALT, AST, GGT and ALP before and after immunotherapy.

\section{Detection of lymphocyte subsets and tumor markers} Lymphocyte subsets were detected by flow cytometry (FACSCanto $^{\mathrm{TM}} \mathrm{II}$; Becton Dickinson, San Jose, CA, USA). Peripheral blood ( $2 \mathrm{~mL}$ ) was drawn to assess the lymphocyte subsets before and after the HANK cell infusion. The number of $\mathrm{CD}^{+}, \mathrm{CD}^{+} \mathrm{CD}^{+}, \mathrm{CD}^{+}{ }^{+} \mathrm{CD} 4^{+}, \mathrm{CD}^{-} \mathrm{CD} 16^{+} \mathrm{CD}^{-} 6^{+}$and $\mathrm{CD} 45^{+}$cells was detected. The level of carbohydrate antigen 19-9 (CA19-9, reference range $<39 \mathrm{U} / \mathrm{mL}$ ) expression was determined by radioimmunoassay (Maglumi 2000 Plus) before and after the HANK cell infusion.

Circulating tumor cells (CTCs) were measured as a biomarker for identification of patients at high risk of relapse and to monitor immune responses to therapy. ${ }^{20,21}$ According to a previously published report, cells that were CD45 negative, $\mathrm{CK}$ positive and CD326 positive were defined as CTCs. ${ }^{10}$ In normal conditions, the reference number of CTCs is $0-1$ cells $/ 7.5 \mathrm{~mL}$ blood. CTCs $\geq 5$ indicate poor prognosis and high risk of recurrence or metastasis. CTCs $<5$ indicate low risk of recurrence or metastasis. The detection procedure includes collect $7.5 \mathrm{~mL}$ blood from the patient and isolate MNCs using human peripheral blood lymphocyte separation solution (Haoyang Biological Manufacture Co., Ltd.). Isolated cells were enriched by binding to magnetic CD326 (Ep-CAM) MicroBeads (Miltenyi Biotec Ltd., Bergisch Gladbach, Germany) using magnetic-activated cell sorting (MACS). Enriched cells were labeled with monoclonal antibodies targeting the epithelial cell antigens CD45, CD326 and cytokeratin 8, 18 and 19 (Miltenyi Biotec Ltd.) and counted by flow cytometry using a BD FACSCanto ${ }^{\mathrm{TM}}$ II apparatus (Becton Dickinson).

\section{CT imaging change}

The changes in CT tumor imaging were monitored to evaluate the curative effect of the treatment according to the evaluation standards published by the $\mathrm{WHO} .^{22}$ According to the degree of change in the largest transverse diameter, the therapeutic effect is categorized as a complete response (CR), disappearance of the arterial enhancement imaging of all target lesions; partial 
Table 2 The result of genotyping of both host and donor

\begin{tabular}{|l|l|l|}
\hline & Donor (patient's kinsfolk) & Recipient (patient) \\
\hline Genotype & KIR2DLI, KIR2DL3, KIR2DS2 & HLA-Cw3, HLA-CwI2 \\
\hline
\end{tabular}

Note: According to a previously published report, we found KIR/HLA-Cw mismatch between donor and the patient.

response $(\mathrm{PR})$, total reduction in the diameter of the target lesions $>30 \%$; stable disease (SD), tumor regression fails to reach $\mathrm{PR}$ or tumor progression fails to reach progressive disease (PD) and PD, total progression of the tumor diameter $>20 \%$. To accurately observe the therapeutic effects, the total area of all tumors before and after treatment was compared. The recent curative effect must be maintained for $>4$ weeks, with $\mathrm{CR}+\mathrm{PR}$ representing the effective rate $(\mathrm{RR})$.

\section{Results}

\section{Genotyping of host and donor}

Following genotyping test, we found KIR/HLA-Cw mismatch between donor and the patient according to previously published report. ${ }^{23}$ The result is given in Table 2.

\section{Identification of HANK cells}

Before NK cell expansion, the median percentage of the $\mathrm{CD}^{-} \mathrm{CD}^{-} 6^{+}$population was $9.2 \%$ (range: $7.2 \%-13.3 \%$ ). Following expansion, the proportion of viable cells exceeded $92 \%$ without any bacterial, fungal or mycoplasma contamination (endotoxin level $<1 \mathrm{EU}$ ). The median proportion of $\mathrm{CD} 6^{+} \mathrm{CD}^{-}{ }^{-}$cells was $86.3 \%$ (range: $80.1 \%-94.8 \%$ ). The representative results are presented in Figure 1.

A

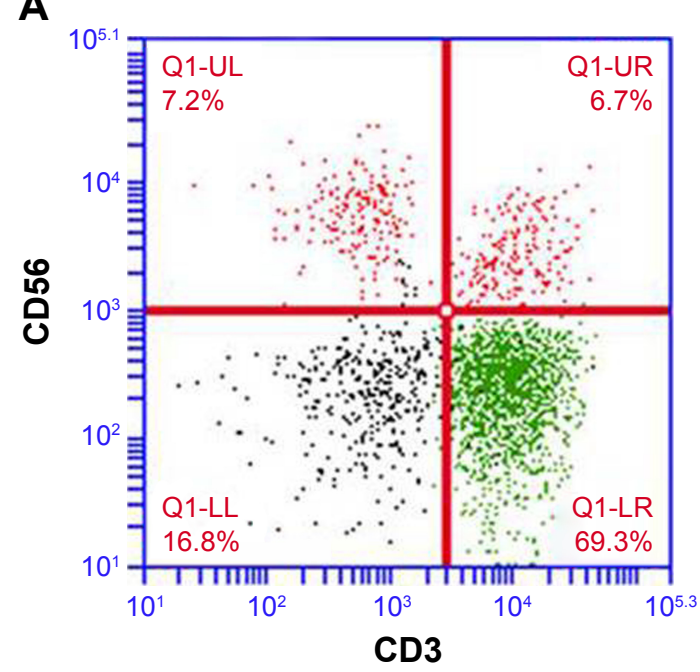

\section{Evaluation of safety and curative effect}

During the HANK cell infusion, the patient did not report experiencing cold chills, fever or any other discomforts. After the treatment, the ALT, AST and GGT levels were reduced compared with the levels detected before treatment, while there was no effect on the ALP levels (Figure 2). The lymphocyte subsets of the patient were improved following allogenic NK immunotherapy (Figure 3). The CA19-9 level increased after HANK cell infusion (Figure 4) but returned to normal numbers after a year, and CTCs also fell back to normal and were even stable after a year (Table 3 ).

\section{CT imaging changes}

Before iodine-125 seed implantation, the metastatic tumor size was $2.2 \times 1.9 \mathrm{~cm}$ (Figure $5 \mathrm{~A}$ ). The size decreased to $2.0 \times 0.9 \mathrm{~cm}$ at 2 months after treatment and $1.7 \times 1.2 \mathrm{~cm}$ after 5 months (Figure 5B and $\mathrm{C}$, respectively). The metastatic tumor size remained stable for at least a year after treatment (Figure 5D). As previously described, the patient achieved a PR following treatment, with an overall survival time of $>18$ months. ${ }^{22}$

\section{Discussion}

For the majority of patients with advanced HCC, the tumor is unresectable. Chemotherapy, radiotherapy and other palliative treatments are options for patients with metastatic disease. ${ }^{24,25}$ A randomized controlled study by Chen et $\mathrm{al}^{26}$ showed that iodine-125 seed implantation therapy following liver resection significantly prolonged the time to recurrence and overall survival rates. Nag et $\mathrm{al}^{27}$ observed high complete or partial remission rates for unresectable HCC following

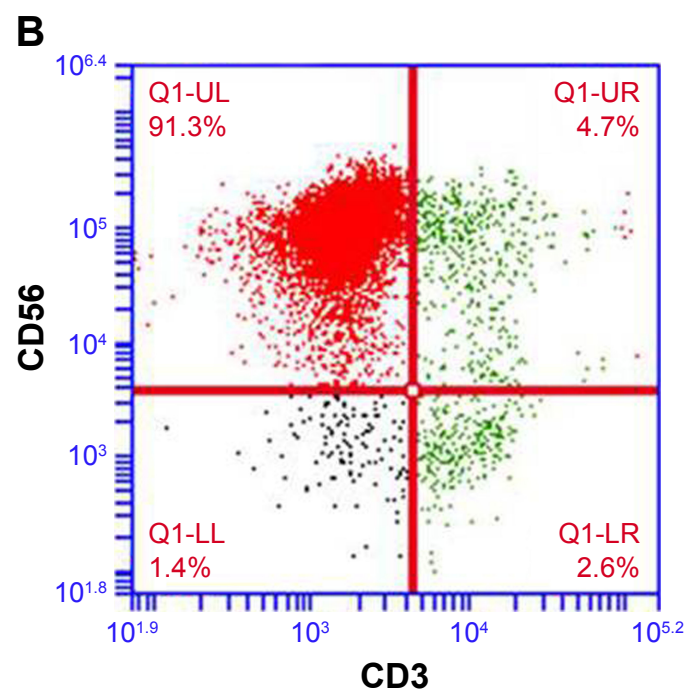

Figure I Proportion analysis of $\mathrm{CD}^{-} \mathrm{CD} 56^{+}$cells (NK cells).

Notes: (A) The proportion of NK cells before the expansion. (B) The proportion of NK cells after the expansion on Day 9.

Abbreviation: NK, natural killer. 

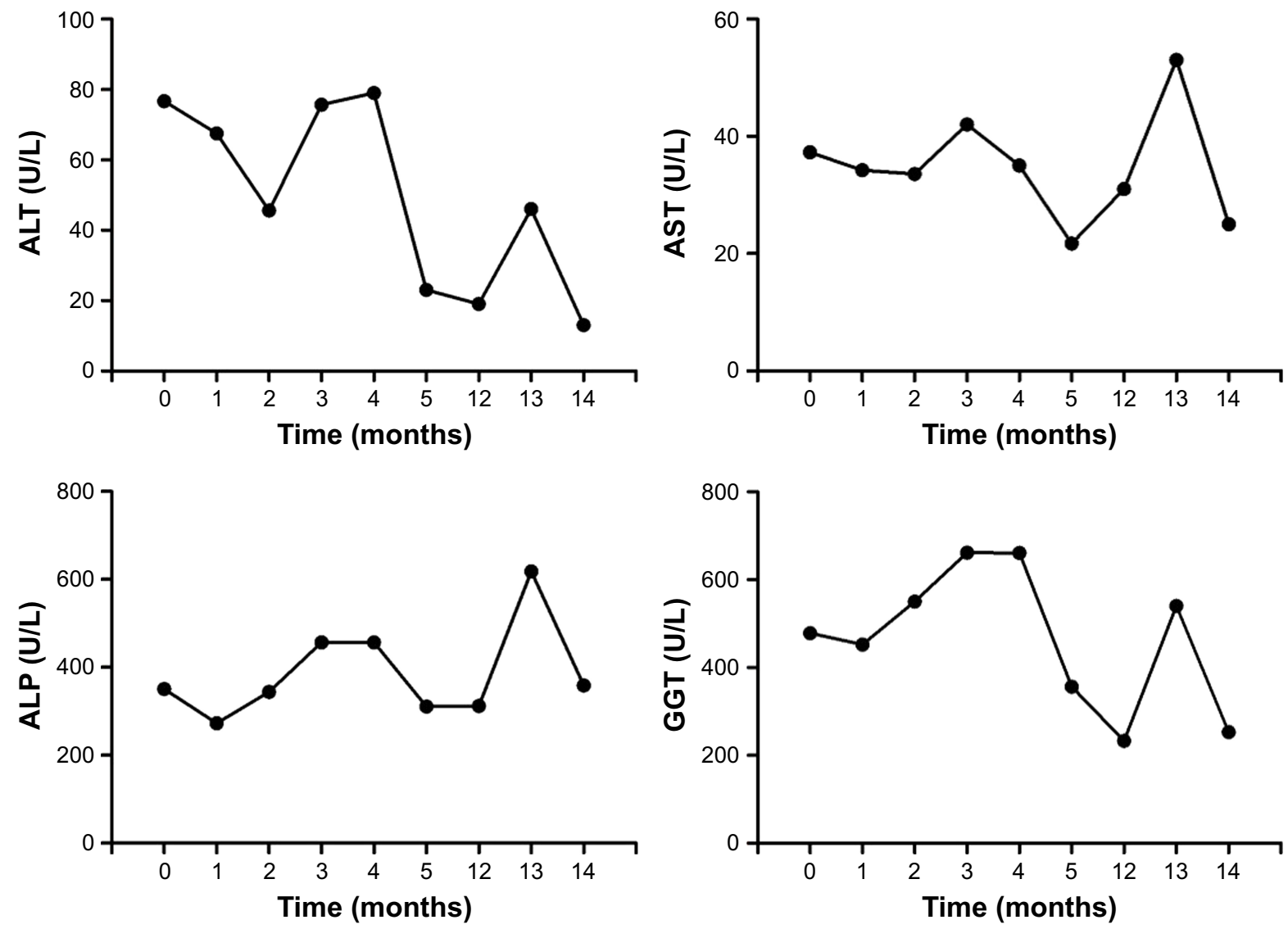

Figure 2 Liver function.

Note: The levels of ALT, AST and GGT were reduced except for ALP after treatment.

iodine-125 therapy. Furthermore, Chuan-Xing et $\mathrm{al}^{28}$ reported that it was effective and safe to perform chemoembolization and implantation of stents with iodine- 125 seeds for patients with HCC and portal vein thrombus. These studies indicated

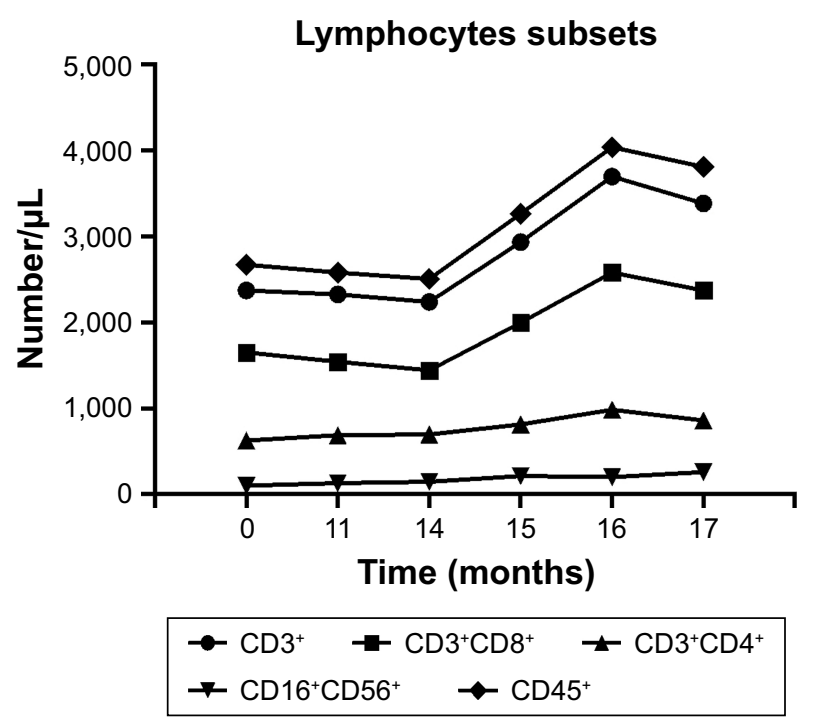

Figure 3 Detection of lymphocyte subsets.

Note: The lymphocyte subsets were gradually increased after iodine- 125 seed implantation combined with allogenic HANK cell immunotherapy.

Abbreviation: HANK, highly activated natural killer. the potential effectiveness of iodine- 125 seed implantation in HCC recurrence therapy after LT. In addition, a prospective study by Chen et a ${ }^{29}$ showed that radiofrequency ablation combined with percutaneous iodine-125 seed implantation $(\mathrm{n}=68)$ results in better 5 -year survival rate $(66.1 \%$ vs $47 \%$, $P=0.003)$ compared with the use of radiofrequency ablation

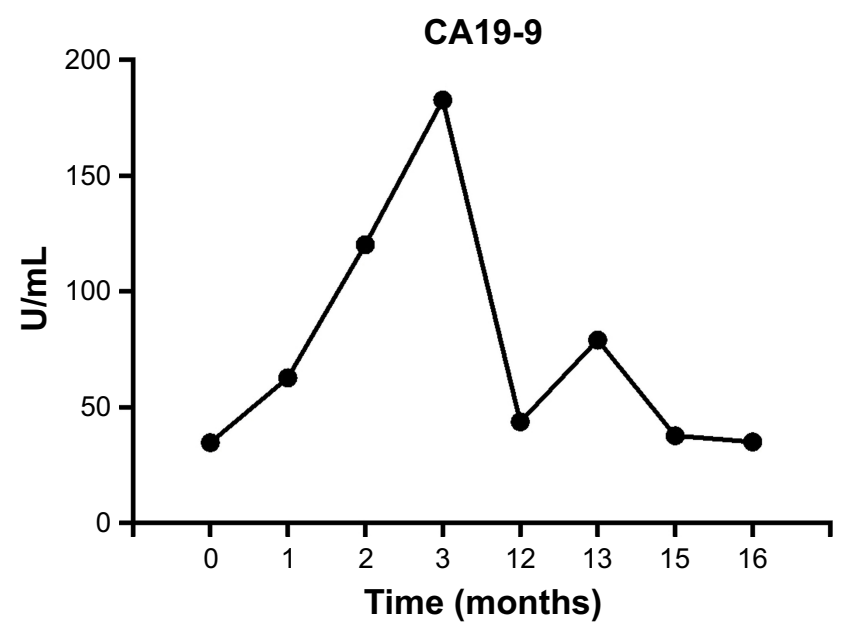

Figure 4 Tumor markers.

Note: CA19-9 levels increased following iodine- 125 seed implantation combined with allogenic NK immunotherapy and reduced to the normal level after a year. Abbreviation: NK, natural killer. 
Table 3 The variation of CTCs numbers

\begin{tabular}{|l|l|}
\hline Date & CTCs \\
\hline July 21, 2016 & 3 \\
\hline August 17, 2016 & 19 \\
\hline August 26, 2016 & 0 \\
\hline August 25, 2017 & 0 \\
\hline October 27, 2017 & 2 \\
\hline December I, 2017 & 0 \\
\hline
\end{tabular}

Notes: CTCs fall back from high values ( 19 cell number $/ 7.5 \mathrm{~mL}$ blood) to normal level (0-I cell number/7.5 mL blood) following treatment and were even stable after a year. Reference: $0-1$ cell/7.5 mL blood.

Abbreviation: CTCs, circulating tumor cells.
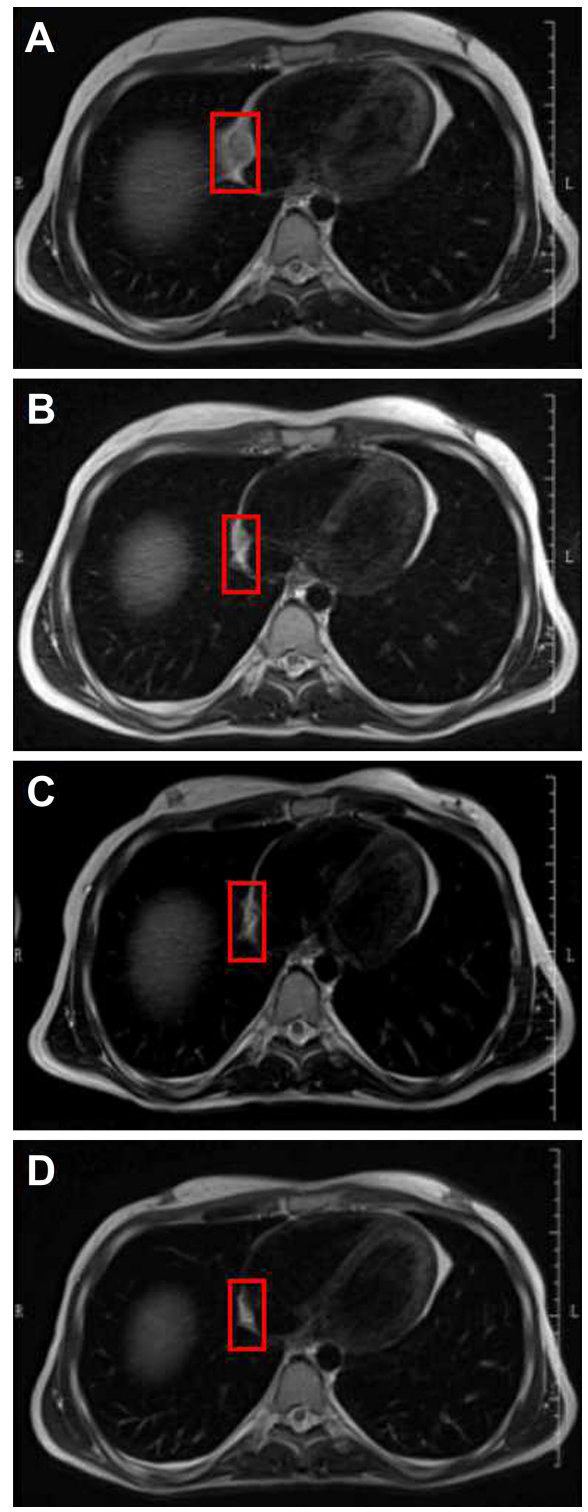

Figure $5 \mathrm{MRI}$ of the patient before and after treatment.

Notes: (A) Lesion before treatment (June 2016): metastatic tumor size $2.2 \times 1.9 \mathrm{~cm}$ (red rectangle). (B) Clinical effect at 2 months after iodine- 125 seed implantation: metastatic tumor size $2.0 \times 0.9 \mathrm{~cm}$ (red rectangle). (C) Clinical effect at 5 months after infusions of allogenic NK cells: metastatic tumor size $1.7 \times 1.2 \mathrm{~cm}$ (red rectangle). (D) Regular follow-up visited at October 2017: metastatic tumor size $1.8 \times 0.9 \mathrm{~cm}$ (red rectangle).

Abbreviations: MRI, magnetic resonance imaging; NK, natural killer. alone $(\mathrm{n}=68)$ in patients with HCC. A case report from Xiong et al also showed that the liver function test was mildly abnormal except for a slight elevation in AST (65 IU/L) and ALT (60 IU/L) after iodine-125 seed implantation in a 48-year-old male patient with primary HCC and pancreatic metastasis. Moreover, the tumor size of the hepatic and metastasis was largely reduced after 15 months follow-up. ${ }^{30}$ Although there is lack of clinical evidence in the tumor reduction in a specific time range, image-guided iodine-125 seed implantation has been regarded as an promising therapeutic approach to unresectable HCC.

In this study, we used the human HANK cell in vitro preparation kit to induce the expansion and activation of KIR-mismatched HANK cells. The patient received transfusions of $1 \times 10^{10}$ HANK cells in each course of treatment. Our clinical data show that allogenic HANK cell immunotherapy achieved a partial clinical response and improved the quality of life of the patient, with no sign of graft vs host reaction (GVHR) or any other local or systemic side effects.

In HCC recurrence therapy after LT, NK cells play at least three important roles. The first role is to directly kill tumor cells. As part of the immune system, NK cells can destroy tumor cells and target cells without antigens or sensitization. NK cells can recognize and lyse cells lacking major histocompatibility complex (MHC) molecules via their activating receptors. Taking advantage of alloreactivity by the "missingself" concept, a mass of studies has shown that infusion of haploidentical NK cells to exploit KIR/HLA alloactivity is safe and allogenic NK cell immunotherapy can obtain a better clinical effect than current approaches. The second role is immunoregulation function, which is very important for transplanted organ survival without immunosuppressive chemotherapy as reported for stem cell transplantation. ${ }^{31,32}$ The third role is the antiviral infection function of the NK cells, which is also crucial to prevent opportunistic viral infections and successful transplantation. ${ }^{33-38}$

In conclusion, we report a case of partial clinical response to allogenic NK cell immunotherapy combined with iodine125 seed implantation in an HCC patient after LT. Our findings provide evidence of the potential therapeutic safety and effectiveness of this regimen, which warrants further investigation in prospective clinical studies.

\section{Disclosure}

The authors report no conflicts of interest in this work.

\section{References}

1. Heysek RV. Modern brachytherapy for treatment of prostate cancer. Cancer Control. 2007;14(3):238-243. 
2. Lazarescu GR, Battista JJ. Analysis of the radiobiology of ytterbium169 and iodine-125 permanent brachytherapy implants. Phys Med Biol. 1997;42(9):1727-1736.

3. NathR, AndersonLL, Luxton G, WeaverKA, WilliamsonJF, Meigooni AS. Dosimetry of interstitial brachytherapy sources: recommendations of the AAPM Radiation Therapy Committee Task Group No. 43. American Association of Physicists in Medicine. Med Phys. 1995;22(2): 209-234.

4. Xiang GA, Chen KY, Wang HN, Xiao JF. Immunological influence of iodine-125 implantation in patients with hepatocellular carcinoma resection. Nan Fang Yi Ke Da Xue Xue Bao. 2010;30(2):292-294.

5. Zhao Y, Hu J, Li R, et al. Enhanced NK cell adoptive antitumor effects against breast cancer in vitro via blockade of the transforming growth factor- $\beta$ signaling pathway. Onco Targets Ther. 2015;8:1553-1559.

6. Cheng M, Chen Y, Xiao W, Sun R, Tian Z. NK cell-based immunotherapy for malignant diseases. Cell Mol Immunol. 2013;10(3):230-252.

7. Nishida S, Levi DM, Tzakis AG. Liver natural killer cell inoculum for liver transplantation with hepatocellular carcinoma. Curr Opin Organ Transplant. 2013;18(6):690-694.

8. Ohira M, Nishida S, Tryphonopoulos P, et al. Clinical-scale isolation of interleukin-2-stimulated liver natural killer cells for treatment of liver transplantation with hepatocellular carcinoma. Cell Transplant. 2012; 21(7):1397-1406.

9. Xie S, Chen J, Zhang M, Wu Z. Allogenic natural killer cell immunotherapy of sizeable ovarian cancer: A case report. Mol Clin Oncol. 2017;6(6):903-906.

10. Lin M, Liang SZ, Shi J, et al. Circulating tumor cell as a biomarker for evaluating allogenic NK cell immunotherapy on stage IV non-small cell lung cancer. Immunol Lett. 2017;191:10-15.

11. Hsu KC, Keever-Taylor CA, Wilton A, et al. Improved outcome in HLA-identical sibling hematopoietic stem-cell transplantation for acute myelogenous leukemia predicted by KIR and HLA genotypes. Blood. 2005;105(12):4878-4884.

12. Witt CS, Christiansen FT. The relevance of natural killer cell human leucocyte antigen epitopes and killer cell immunoglobulin-like receptors in bone marrow transplantation. Vox Sang. 2006;90(1):10-20.

13. Forte P, Baumann BC, Schneider MK, Seebach JD. HLA-Cw4 expression on porcine endothelial cells reduces cytotoxicity and adhesion mediated by CD158a+ human NK cells. Xenotransplantation. 2009 16(1):19-26.

14. Kunert K, Seiler M, Mashreghi MF, et al. KIR/HLA ligand incompatibility in kidney transplantation. Transplantation. 2007;84(11):1527-1533.

15. Moretta L, Moretta A. Killer immunoglobulin-like receptors. Curr Opin Immunol. 2004;16(5):626-633.

16. Lin $\mathrm{M}$, Liang $\mathrm{S}$, Wang $\mathrm{X}$, et al. Cryoablation combined with allogenic natural killer cell immunotherapy improves the curative effect in patients with advanced hepatocellular cancer. Oncotarget. 2017;8(47): 81967-81977.

17. Lin M, Alnaggar M, Liang S, et al. An important discovery on combination of irreversible electroporation and allogeneic natural killer cell immunotherapy for unresectable pancreatic cancer. Oncotarget. 2017; 8(60):101795-101807.

18. Leung W, Iyengar R, Turner V, et al. Determinants of antileukemia effects of allogeneic NK cells. J Immunol. 2004;172(1):644-650.

19. Zhang M, Daniel S, Huang Y, et al. Anti-West Nile virus activity of in vitro expanded human primary natural killer cells. BMC Immunol. 2010;11:3.

20. Nguyen DX, Bos PD, Massagué J. Metastasis: from dissemination to organ-specific colonization. Nat Rev Cancer. 2009;9(4):274-284.

21. Alix-Panabières $\mathrm{C}$, Pantel K. Circulating tumor cells: liquid biopsy of cancer. Clin Chem. 2013;59(1):110-118.
22. Miller AB, Hoogstraten B, Staquet M, Winkler A. Reporting results of cancer treatment. Cancer. 1981;47(1):207-214.

23. Delgado DC, Hank JA, Kolesar J, et al. Genotypes of NK cell KIR receptors, their ligands, and Fc $\gamma$ receptors in the response of neuroblastoma patients to Hu14.18-IL2 immunotherapy. Cancer Res. 2010; 70(23):9554-9561.

24. Goldberg SN, Grassi CJ, Cardella JF, et al. Image-guided tumor ablation: standardization of terminology and reporting criteria. J Vasc Interv Radiol. 2009;20:s377-390.

25. Eisenhauer EA, Therasse P, Bogaerts J, et al. New response evaluation criteria in solid tumours: revised RECIST guideline (version 1.1). Eur J Cancer. 2009;45(2):228-247.

26. Chen K, Xia Y, Wang H, Xiao F, Xiang G, Shen F. Adjuvant iodine-125 brachytherapy for hepatocellular carcinoma after complete hepatectomy: a randomized controlled trial. PLoS One. 2013;8(2):e57397.

27. Nag S, DeHaan M, Scruggs G, Mayr N, Martin EW. Long-term follow-up of patients of intrahepatic malignancies treated with iodine-125 brachytherapy. Int J Radiat Oncol Biol Phys. 2006;64(3): 736-744.

28. Chuan-Xing L, Xu H, Bao-Shan H, et al. Efficacy of therapy for hepatocellular carcinoma with portal vein tumor thrombus: chemoembolization and stent combined with iodine-125 seed. Cancer Biol Ther. 2011;12(10): $865-871$.

29. Chen $\mathrm{K}$, Chen $\mathrm{G}$, Wang $\mathrm{H}$, et al. Increased survival in hepatocellular carcinoma with iodine-125 implantation plus radiofrequency ablation: a prospective randomized controlled trial. J Hepatol. 2014;61(6): 1304-1311.

30. Xiong J, Kwong Chian S, Li J, Liu X. Iodine-125 seed implantation for synchronous pancreatic metastases from hepatocellular carcinoma: A case report and literature review. Medicine (Baltimore). 2017;96(46): e8726.

31. Shaffer BC, Le Luduec JB, Forlenza C, et al. Phase II Study of Haploidentical Natural Killer Cell Infusion for Treatment of Relapsed or Persistent Myeloid Malignancies Following Allogeneic Hematopoietic Cell Transplantation. Biol Blood Marrow Transplant. 2016;22(4): 705-709.

32. Lee DA, Denman CJ, Rondon G, et al. Haploidentical Natural Killer Cells Infused before Allogeneic Stem Cell Transplantation for Myeloid Malignancies: A Phase I Trial. Biol Blood Marrow Transplant. 2016; 22(7):1290-1298.

33. Miller JS, Soignier Y, Panoskaltsis-Mortari A, et al. Successful adoptive transfer and in vivo expansion of human haploidentical NK cells in patients with cancer. Blood. 2005;105(8):3051-3057.

34. Rubnitz JE, Inaba H, Ribeiro RC, et al. NKAML: a pilot study to determine the safety and feasibility of haploidentical natural killer cell transplantation in childhood acute myeloid leukemia. J Clin Oncol. 2010;28(6):955-959.

35. Curti A, Ruggeri L, D’Addio A, et al. Successful transfer of alloreactive haploidentical KIR ligand-mismatched natural killer cells after infusion in elderly high risk acute myeloid leukemia patients. Blood. 2011;118(12):3273-3279.

36. Iliopoulou EG, Kountourakis P, Karamouzis MV, et al. A phase I trial of adoptive transfer of allogeneic natural killer cells in patients with advanced non-small cell lung cancer. Cancer Immunol Immunother. 2010; 59(12):1781-1789.

37. Re F, Staudacher C, Zamai L, Vecchio V, Bregni M. Killer cell Ig-like receptors ligand-mismatched, alloreactive natural killer cells lyse primary solid tumors. Cancer. 2006;107(3):640-648.

38. Geller MA, Cooley S, Judson PL, et al. A phase II study of allogeneic natural killer cell therapy to treat patients with recurrent ovarian and breast cancer. Cytotherapy. 2011;13(1):98-107. 


\section{Publish your work in this journal}

OncoTargets and Therapy is an international, peer-reviewed, open access journal focusing on the pathological basis of all cancers, potential targets for therapy and treatment protocols employed to improve the management of cancer patients. The journal also focuses on the impact of management programs and new therapeutic agents and protocols on

patient perspectives such as quality of life, adherence and satisfaction. The manuscript management system is completely online and includes a very quick and fair peer-review system, which is all easy to use. Visit http://www.dovepress.com/testimonials.php to read real quotes from published authors.

Submit your manuscript here: http://www.dovepress.com/oncotargets-and-therapy-journal 